Kalpa Publications in Engineering
Volume 1, 2017, Pages 457-463
ICRISET2017. International Conference on Re-
search and Innovations in Science, Engineering
\&Technology. Selected Papers in Engineering

\title{
Performance Analysis, Savings and Modifications in Compressed Air System of Manufacturing Industry
}

\author{
Yogesh R Prajapati ${ }^{1}$, Jatinkumar J Patel ${ }^{2}$, Shweta Y Prajapati ${ }^{3}$ and Manish \\ N Sinha ${ }^{4}$ \\ ${ }^{1,4}$ Assistant Professor, BVM Engineering College, Vallabh Vidyanagar \\ yrprajapati@bvmengineeringa.ac.in, mnsinha@bvmengineering.ac.in \\ ${ }^{2}$ Associate Professor, GCET, Vallabh Vidyanagar \\ jjpatelgcet@gmail.com \\ ${ }^{3}$ Lecturer, BBIT, Vallabh Vidyanagar \\ syp.mee@gmail.com
}

\begin{abstract}
In the present scenario importance of an energy conservation increased day by day. There are various utilities in industries in practice like Chillers, Cooling Towers, Blowers, Fans, Motors, Furnaces, Pumps and Air Compressors in manufacturing industries plays vial role in energy consumption. Energy savings is possible increasing either the efficiency or replacement by efficient utility. It has been found that among all the utilities, Air Compressors are the least efficient utilities. It has been observed that compressed air system installed in early stage and due to ageing effect as well as lack of maintenance an efficiency of compressor is dropped down. In proposed work, Performance analysis of four air compressors has been carried out using "pump up test" (PUT) and losses by "leakage test" at different locations has been calculated large scale gear manufacturing industry. Considerable solution in terms of savings has been provided by providing priority base run of air compressors. Additional solution with variable frequency drive has also been also proposed. It has been proved that alternation of both mentioned test able to provide 5-15\% additional amount of energy savings.
\end{abstract}




\section{Introduction}

In Indian industries, one of the most important utility an air compressor uses manor amount of electricity. In air compressors, electrical energy is converted into pressurized air which is stored in storage tank called as a receiver. From the receiver, this air is used to supply process requirements like, different pneumatic operations like drying, cleaning and required instrument air. From the literature it has been noted that out of $100 \%$ energy consumption by air compressor, up to the end point $10-30 \%$ energy reaches while left over value of energy is wasted into unusable heat energy by means of unused power of the air compressor which is finally converted into in form of friction, noise, operational misuse which is 70-90 \% [1]. Positive displacement and Dynamic air compressors are the two basic classifications of air compressors. Positive displacement air compressors reduces an air pressure by reducing the volume and Dynamic air compressor generate pressurized air by first increasing velocity of an air and finally converted in to pressurized air at outlet [2]. Positive displacement compressors are further classified as reciprocating and rotary compressors. Dynamic compressors are mainly centrifugal compressors. Axial flow and Radial flow are the two types of dynamic compressors. On and off operation of an air compressor dependent on air consumption at end user side, which decides the loading and unloading power consumption $(\mathrm{KWH})$ ? In manufacturing plant, compressors are running in a corrosive and high temperature conditions. So upgrading the design of the compressor unit can increase the reliability, safety and overall efficiency of the compressor. Annual operating costs of compressed air can be considered up to $70 \%$ to $90 \%$ of the total electricity bill for specific users, which is very expensive in case of misuse [3]. In [4] author has discussed the role of compressed air energy system (CAES) for future sustainable energy system by combining CAES with renewable energy sources. In [5] developed control strategy for different types of control valve has been discussed. Following are the most common control strategies:

1. Variable Speed: The variable frequency drive, which varies the speed of the compressor, so flow, will vary as per air demand.

2. Start-Stop: Air compressor is switched on and off by pressure switch. It will on when system pressure is above generated pressure. In every startup an amount of current required to the motor is higher as compared that under regular workload, so the life of the motor reduces.

3. Load-Unload: When system (outlet) pressure is more than the compressor set pressure, then compressor will run in full load condition and when compressor pressure reached set pressure it will run in unload mode. But during unload running mode compressor consuming approximately $20-20 \%$ of the power even it is not generating any air. Also the pressure fluctuation due to the swing between level of set pressure and system pressure is responsible for the downstream the plant.

4. Inlet Modulation: In this control for the variation in an air flow the inlet air valve is constantly adjusted in order to meet an air demand.

5. Variable Displacement: Variable displacement is possible with the help of variable frequency drive (VFD). It gives maximum benefit when efficient compressor is run through VFD. One has to identify the leakages and efficient compressor for giving priority. 


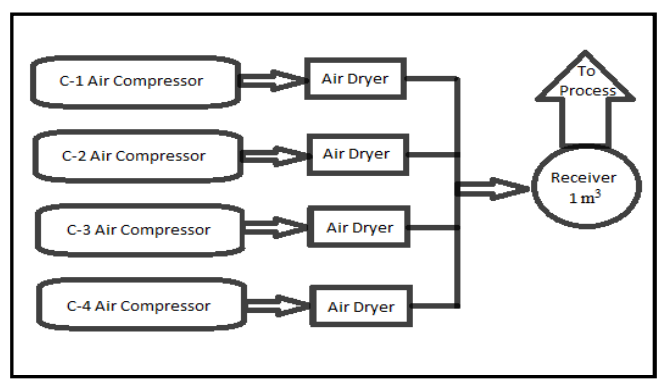

Figure 1: Block diagram of an Air Compressor

\section{Performance assessment of parameters of CAES}

As shown in fig. 1 four air compressors are connected in parallel with common header. Air is delivered to the process through receiver of $1 \mathrm{~m}^{3}$. An air requirement of a plant is $6.5 \mathrm{~kg} / \mathrm{cm}^{2}$.Only one compressor is running out of four, which fulfill the requirement of an air. Second compressor is on in case of air requirement above set pressure, which is $7 \mathrm{~kg} / \mathrm{cm}^{2}$. Power supply is given to air compressor in star delta mode. The performance analysis of an Air compressor includes free air delivery test, leakage test (FAD) and power consumption.

\subsection{Instruments Required For Measurement.}

$>$ Thermocouple for temperature $\left(0-200{ }^{\circ} \mathrm{C}\right)$.

$>$ Pressure gauge for pressure measurement $\left(0-10 \mathrm{~kg} / \mathrm{cm}^{2}\right.$.

$>$ Timer/Stop Watch to measure time (Min.)

$>$ Power Analyzer. $(0-100 \mathrm{~A}, 0-440 \mathrm{~V} \mathrm{rms}, 50 \mathrm{~Hz})$

\subsection{Calculation Of Free Air Delivery (FAD) By Pump Up Test}

The FAD of the compressor by "Pump Up Method" which is also known as "Receiver Filling Method" is proceed by following steps in practice by Bureau of Energy Efficiency(BEE) audited Indian Industry of pump up method [1]. The following steps has been followed to perform test.

First of all by strongly closing an isolation valve receiver outlet will close and also isolate the compressor with individual receiver (Separate compressor receiver unit from from other couplings) .

$>$ Empty the receiver and pipeline from air and drain out water by opening water drain valve. Keep that water trap line is tightly closed and start test.

$>$ Activate the stop watch when to start the compressor to not down load (air filling) time. Note down initial pressure $\mathrm{P}_{1}$, final Pressure $\mathrm{P}_{2}$ (When compressor is unload.).

$>$ Calculate, Actual FAD is:

$$
Q=\left\{\frac{\left(P_{2}-P_{1}\right)}{P_{0}}\right\} *\left(\frac{V}{T}\right) N^{3} / \text { Min. }
$$

Where $\mathrm{P}_{1}=$ Initial pressure on receiver $\left(\mathrm{kg} / \mathrm{cm}^{2}\right), \mathrm{P}_{2}=$ Final pressure of receiver $\left(\mathrm{kg} / \mathrm{cm}^{2}\right), \mathrm{P}_{0}=$ Atmospheric Pressure $\left(\mathrm{kg} / \mathrm{cm}^{2}\right), \mathrm{V}=$ Volume of reviver $\left(\mathrm{m}^{3}\right)$ (Including receiver, after cooler, and delivery piping), $\mathrm{T}=$ Time take to build up pressure to $\mathrm{P}_{2}$ in minutes. 


\subsection{Calculation Of Leakages}

There is a major energy saving opportunity by preventing leakages in compressed air lines. Various locations of leakages are often found at relief valve, air receivers, hose joints, pipes, tools, pipes shut off valves and couplings. Mostly losses are due to improper installation and poor maintenance. The following steps have been followed to carry out test.

$>$ The test has been conduct after shutting off all air operated equipments and close the valves of equipments.

$>$ Start the compressor and deliver the air on operating pressure. Do not open equipment valve.

$>$ Record the time of "Load Cycle" and "Unload Cycle" of an air compressor. Repeat it for 8 to 10 cycles.

$>$ Calculate, the system leakage is:

$$
\text { System Leakage }=Q *\left(\frac{T}{T+t}\right)
$$

Where $\mathrm{Q}=$ Air delivered to supplied $\left(\mathrm{m}^{3} / \mathrm{min}\right) . \mathrm{T}=$ Load time of compressor $(\mathrm{Min}) . \mathrm{t}=$ Unload time of compressor (Min).

$$
\begin{aligned}
& S P C=\left(\frac{\text { Load }, K W H}{C C * 60}\right) K W H / m^{3} \\
& \text { Energy Lost }=S P C * \text { Leakage }
\end{aligned}
$$

Where $\mathrm{CC}=$ Compressor Capacity, $\mathrm{SPC}=$ Specific Power Consumption.

\subsection{Calculation Of Power Consumption}

Power Analyzer has recorded power consumption (KW) for the duration of test. Power (KW) has been recorded using power analyzer during pump up test. Figure 2 to 5 shows power consumption in (KW) during loading and unloading condition of air compressor. Loading power is the average power from air pressure reaches from $\mathrm{P}_{1}$ to $\mathrm{P}_{2}$ and unloading power is the power when air compressor is running at pressure $\mathrm{P}_{2}$.

\section{Performance Analysis Of CEAS}

The following table shows the actual airflow (m3/minute) or in Cubic flow per minute (cfm) of an four different air compressors. Air compressor C-1 is in continuous practice and C-2 is running when air requirement is there. Compressor C-3 and C-4 were occasionally run. From the TABLE. I by comparing the actual $\mathrm{m}^{3} / \mathrm{min}$ and power consumption $(\mathrm{KW})$ data air compressor $\mathrm{C}-3$ is efficient. Because its efficiency is high and it can generate more air $\left(5.6 \mathrm{~m}^{3} / \mathrm{min}\right)$ with less power consumption $(25.91 \mathrm{KW})$ as compared to other three. So, It has been recommended to run air compressor C-3 in continuous practice. All the air compressors are running with star delta starter, so it has been recommended that to install variable frequency drive, which give $5 \%$ to $15 \%$ additional power savings. Table II shows the leakage performance and loss calculation of only one air compressor (C1). The unit rate of 8 Rs. has been considered from the 12 month bill analysis. Compressed air is normally in instruments or process. So after long running period of the plant there will be air leakages, which is the loss of energy. Normally the leakages found in valve or tapings. So it has been recommended to identify the leakages and remove the leakages. 


\begin{tabular}{cccccc}
\hline Parameter & Unit & C-1 & C-2 & C-3 & C-4 \\
\hline Compressor Capacity & $\mathrm{m}^{3} / \mathrm{min}$ & 5.65 & 5.65 & 5.65 & 5.65 \\
Rated CFM & $\mathrm{CFM}$ & 200 & 200 & 200 & 200 \\
Rated KW & $\mathrm{Kw}$ & 37 & 37 & 37 & 37 \\
Actual KW (Load) & $\mathrm{Kw}$ & 31.66 & 32.94 & 25.91 & 35 \\
Running Hours & $\mathrm{Hours}$ & 24 & 12 & - & - \\
Receiver Volume & $\mathrm{m}^{3}$ & 1 & 1 & 1 & 1 \\
Initial Pressure, P1 & $\mathrm{kg}^{2} \mathrm{~cm}^{2}$ & 0 & 0 & 0 & 0 \\
Final Pressure, P2 & $\mathrm{kg} / \mathrm{cm}^{2}$ & 7 & 7.1 & 6.5 & 6.5 \\
Ambient Pressure, P0 & $\mathrm{kg} / \mathrm{cm}^{2}$ & 1.09 & 1.09 & 1.09 & 1.09 \\
Time & $\mathrm{Min}$ & 1.20 & 1.18 & 1.00 & 1.11 \\
Free Air Delivery & $\mathrm{m}^{3} / \mathrm{min}$ & 5.37 & 5.54 & 5.6 & 5.39 \\
Actual CFM & $\mathrm{CFM}$ & 189.9 & 195.9 & 211.6 & 190.6 \\
& $\mathrm{Kw} / \mathrm{CFM}$ & 0.17 & 1 & 4 & 7 \\
& & & & & \\
\hline
\end{tabular}

Table 2: Pump up test of CAES.

\begin{tabular}{ccc}
\hline Parameter & Unit & C- 1 \\
\hline Load Time & $\mathrm{min}$ & 4.54 \\
Unload Time & $\mathrm{min}$ & 8.07 \\
System Leakage & $\mathrm{m}^{3} / \mathrm{min}$ & 1.59 \\
System Leakage, ,m3/day & $\mathrm{m}^{3} / \mathrm{day}$ & 2291.03 \\
Load & $\mathrm{KW}$ & 31.66 \\
Unload Load & $\mathrm{KW}$ & 11.25 \\
Specific Power Consumption & $\mathrm{m}^{3} / \mathrm{day}$ & 0.0982365 \\
Energy Lost & $\mathrm{KWH}$ & 225.06359 \\
Unit Rate & $\mathrm{Rs}$. & 8 \\
Loss In Rs. & Rs./Day & 1800.5087 \\
Loss In Rs. & Rs./Monthly & 36010.175 \\
Loss In Rs. & Rs./Year & 450127.18 \\
\hline
\end{tabular}

Table 1: Pump up test of CAES.

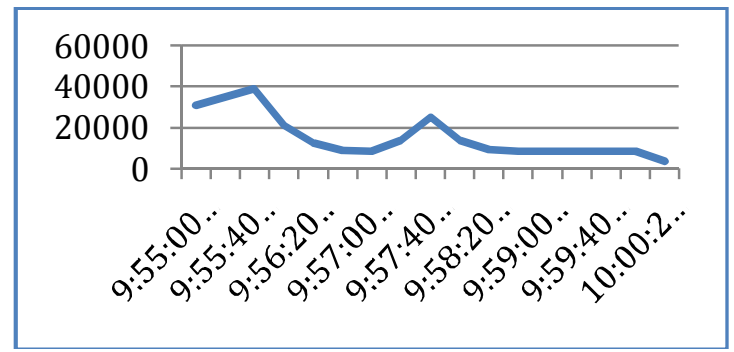

Fig.2 C-1 Power Consumption Pattern. Load Power $=31.66 \mathrm{KW}$, Unload Power $=11.25 \mathrm{KW}$ 


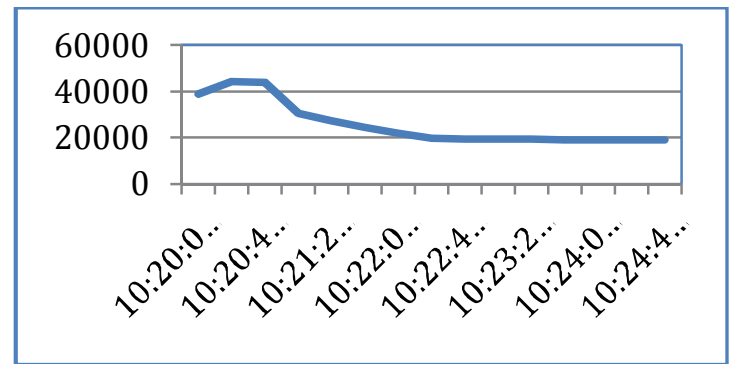

Fig.3 C-2 Power Consumption Pattern Load Power $=32.94 \mathrm{KW}$, Unload Power= 19.23 KW.

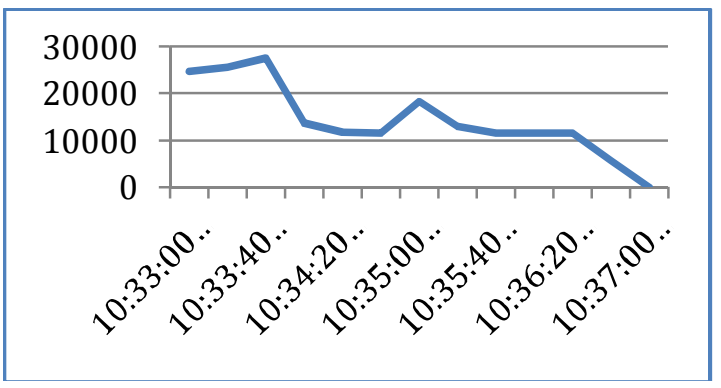

Fig.4 C-3 Power Consumption Pattern Load Power $=25.91 \mathrm{KW}$, Unload Power $=11.86 \mathrm{KW}$.

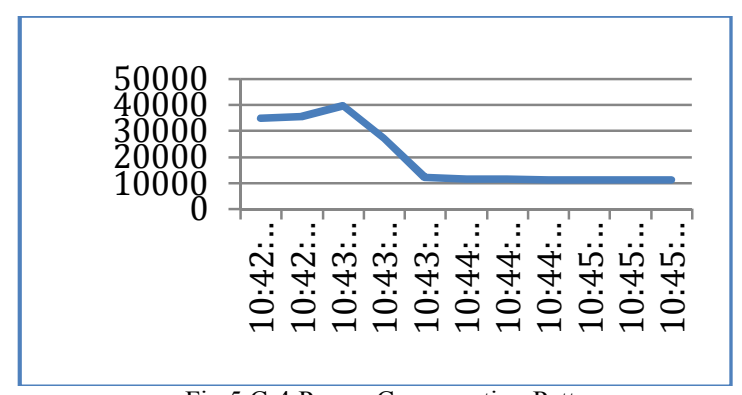

Fig.5 C-4 Power Consumption Pattern Load Power $=34.32 \mathrm{KW}$, Unload Power $=11.82 \mathrm{KW}$.

\section{Conclusion}

It has been observed that compressed air is used as instrumentation air and process air. Due to the leakages there is a loss of energy (29-35\%). After performing the Pump up Test, an efficient air compressor with less power consumption has been evaluated in table no.1. It has been observed that air compressor is the least efficient equipment in any manufacturing industry in practice. Moreover solution is suggested for present running air compressor is that reduction in leakage is $1.59 \mathrm{~m}^{3} / \mathrm{min}$ as discussed above. In such condition, there should be a periodic (Weekly or Monthly) testing of compressor during routine maintenance is highly recommended for gear manufacturing industries. 


\section{References}

https://beeindia.gov.in/sites/default/files/3Ch3.pdf.

P. Pondrano, N. Anglani, and G. Petrecca (2001). "Simulation, planning and control of a central compressed air plant for a more efficient energy use," in 6th Annual International Conference on

Industrial Engineering T heory, Applications and Practice.

R. Saidur, N. Rahim, and M. Hasanuzzaman (2010) "A review on compressedair energy use and energy savings," Renewable and Sustainable Energy Reviews, vol. 14, no. 4, pp. 1135-1153.

Henrik Lund, Georges Salgi (2009) "The role of compressed air energy storage (CAES) in future sustainable energy systems" H. Lund, G. Salgi / Energy Conversion and Management vol. 50,

pp.1172-1179.

C. Schmidt and K. Kissock, ( May 2003) "Power characteristics of industrial air compressors, “ in National Industrial Energy Technology Conference Energy System Laboratory (http://esl. tamu. edu). 